\title{
A Certain Marine Catenate Dinoflagellate Tentatively Applied for Detecting Carcinogens
}

\author{
Shinya IsHIO*, Jiann Chu CHEN* and Tomoki YANO*
}

(Received August 23, 1976)

\begin{abstract}
A marine catenate dinofiagellate having been tentatively applied by the present authors for detecting carcinogens has been regarded to be Polykrikos schwartzi BürsCHLI. However, this species does not belong to the genus Polykrikos for reasons that it is devoid of both syncytium cell structure and nematocysts, but possesses both chloroplasts and phagocytes. This dinoflagellate is now concluded to belong to the genus Gyrodinium from the theca having both blisters and cortical vesicles, plastids very similar to those of Gyrodinium cohnii and the girdle displacement of 0.23 clearly exceeding the upper limit of that of Gymnodinium.
\end{abstract}

A marine red alga, Porphyra tenera produces tumors on their fronds, if exposed to carcinogens such as 3, 4-benzopyrene and benzanthrone in an artificial sea water such as Provasoli's $\mathrm{ASP}_{2}$ NTA medium $^{11}$. However, it takes 32 to 50 days until the fronds indicate the symptom of the affection with the offensive tumors ${ }^{2}$. During these long periods, the carcinogens in the sample water tended to precipitate themselves or adhere on the container walls, otherwise they were incorporated into microorganisms coexisting naturally in the sample water. The consequent denaturation of the sample water often made the tests impossible to continue. Therefore, it is necessary to perform these tests in short periods for detecting carcinogens in sea water. For this object, Porphyra tenera is unsuitable as a test organism. Furthermore, it was quite difficult to confirm the heredity of tumors or anything like tumors induced by substances in the test water when Porphyra tenera was used, because of the difficulty of pursuing the affection for their intricated life cycle through the conchocelis stage and also the difficulty of detecting the abnormalities on chromosomes owing to their inditsinct feature.

In contrast with this, if marine catenate dinoflagellates could be used for testing carcinogens, we could detect with short latent periods the abnormalities on their cell divisions as mitotic delays relating closely to carcinogenesis ${ }^{27}$, and could make sure more easily and precisely the heredity of these abnormalities by inoculating them over generations and calculating their cell fission periods, because they could absorb more quickly the carcinogens into their cells from the external medium and their generation times could be by far shorter than such a multicellular organism as Porphyra tenera.

The most superior point would be that the majority of dinoflagellates, as pointed out by ZINGMARK $^{3}$, have the distinct chromosomes in their nuclei and make possible to

* Lab. Fish. Chem., Fac. Agr., Kyushu Univ., Fukuoka, Japan (石尾真弥・陳 建初・矢野友紀：九 州大学農学部水産学科). 
confirm the abnormalities on both chromosomes and chromonemata caused by carcinogens through electron microscopic studies. It would be also the superior feature of dinofllagellates that the nonthecate types can utilize for investigating the incorporation of tritium labelled carcinogens into the organelles by fractional centrifugation, even though their specific activity are not so high for E. M. autoradiography, but not with Porphyra tenera which has unbreakable cell walls.

With these reasons and the well-known nutrition, the present authors used a certain marine catenate dinoflagellate, which was purely cultured and classified to be Polykrikos schwartzi BüTSCHLI by IWASAKI ${ }^{4}$, and endeavored for establishing a quick bioassay of the carcinogens discharged into sea waters. In the meanwhile, we became aware of the erroneous classification of this dinoflagellate from the observation of the electron micrographs of this microorganism and concluded that this species belongs to the genus Gyrodinium but not the genus Polykrikos.

Hence, we attempt to deal with the reasons obtained through the microscpoic and the electron microscopic observations.

\section{Materials and Methods}

Dinoflagellate as test organism A certain catenate dinoflagellate was used which had been isolated from the red tide waters along the coast of Fukuyama of Hiroshima prefecture on July in 1969 by IWASAKI ${ }^{4}$ and has been cultured in aseptic condition ever since that time. This dinoflagellate also has been regarded to be Polykrikos schwartzi BütschlI and well studied on its nutritional demand by him.

Cultivation Sixty $\mathrm{m} l$ of Provasoli's medium was taken in each $100 \mathrm{~m} l$ Elrenmyer flask, pluged with a cotton piece and autoclaved for 20 minutes under the pressure of $1 \mathrm{Kg} /$ $\mathrm{cm}^{2}$. After cooling, this medium was inoculated with the dinoflagellate in aseptic condition, and kept statically under the illuminating intensity 6,000 $\mathrm{kx}$ of daylight fluorescent lamps, the light period from 6:00 A.M. to 6:00 P.M. and successively the dark period from 6:00 P.M. to 6:00 A.M. at $20 \pm 0.5^{\circ} \mathrm{C}$ during the cultivation.

Microscopic observation The Nikon AFM microscope was used for observing the living cells of this dinoflagellates.

Fixation and Embedding Ten $\mathrm{ml}$ bottom water of culturing medium containing dense living cells of this species was transferred into a $30 \mathrm{~m} l$ fixing bottle. Ten $\mathrm{m} l$ of 12 volume persent glutaraldehyde $\mathrm{ASP}_{2}$ NTA solution was then added to the fixing bottle and fixed by keeping gentle swirling overnight. This mixture was centrifuged, and the supernatant was discarded. Twenty $\mathrm{ml} \mathrm{ASP}{ }_{2} \mathrm{NTA}$ medium was added, shaking gently, to the precipitate left in a centrifuging tube, then the mixture was centrifuged. This operation was repeated three times for washing out the excess fixatives. The pellet of cells thus obtained from the centrifuging tube was cut off to make the size about $1 \mathrm{~mm}$ cubes and fixed 
with 1 percent osmic acid for 2 hours. The fixed sample was dehydrated with acetone series from $65 \%$ at the start to $100 \%$ at the last and acetone in the fixed sample was substituted with the substitutives QY-1 of Ohken Co., then embedded in epoxy resin through polymerizing at $35^{\circ} \mathrm{C}$ for 1 day, at $45^{\circ} \mathrm{C}$ overnight and at $60^{\circ} \mathrm{C}$ for 2 days.

Preparation of sections and electron staining The ultrathin sections were so prepared using a PORTER-Bulum MT-1 type microtome attached with a glass knife as to make the thickness $800 \AA$ when judged by interference color. These sections were stained for 15 minutes with lead acetate ${ }^{\text {(1) }}$.

Electron microscopic observation Nihon Denshi JEM-7 type electron microscope was used for observing these stained sections on copper meshes.

\section{Results and discussion}

This species displayed to produce monocellular, dicellular and most abundantly tetracellular forms, occasionally octacellular forms during the cultivation. Their external aspects are indicated in Fig. 1.

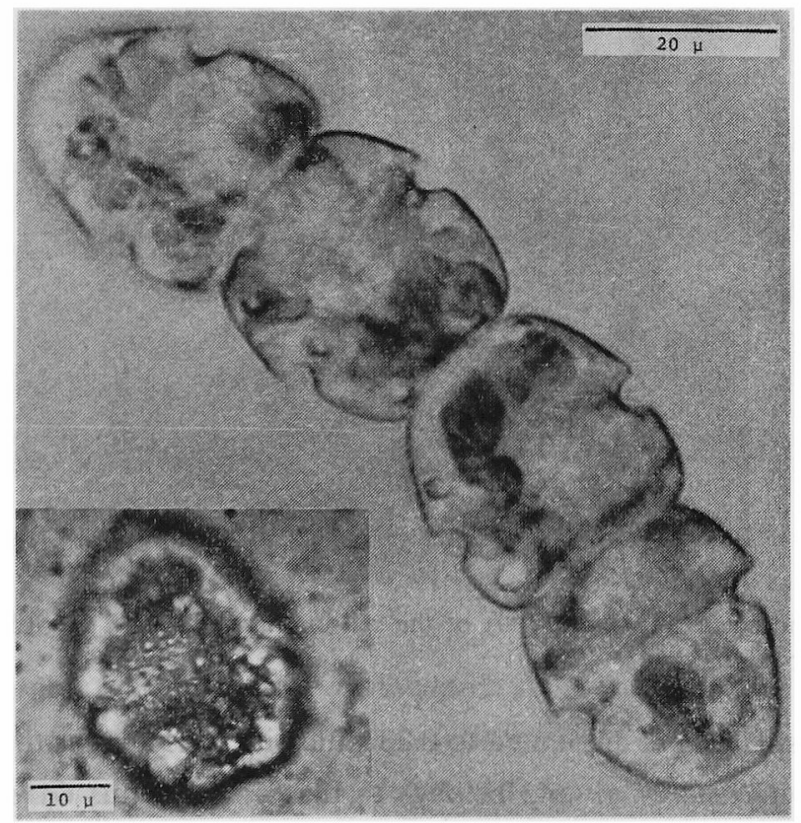

Fig. 1. Tetracellular catena of this species and girdle on the dorsal part. Individual cells of the catena have a huge nucleus each.

The body length of the monocellular forms varied from $24 \mu$ to $60 \mu$ and the average was estimated to be $38.6 \mu$. With the dicellular and tetracellular forms, the average length of these individual cells were shown to be considerably shorter than that of the monocel- 
lular forms: these average values were $27.4 \mu$ for the dicellulars and $26.6 \mu$ for the tetracellulars, respectively.

The individual cell of catenae clearly indicated to shrink its cell length by $11-12 \mu$ and showed to be $70 \%$ as long as the cell length of the monocellular form. The cell width ranged from $21 \mu$ to $40 \mu$ regardless of either the monocellular form or the catenate forms and the average cell width was evaluated to be $29 \mu$.

The girdle of this species is descending spiral and passes nearly along an equator on the dorsal part as shown in Fig. 1.

This pattern differs from Cochlodinium, Amphidinium or Hemidinium. On the ventral part, there is a considerable difference between the levels of the initiation and the termination of the girdle as shown in Fig. 2 .

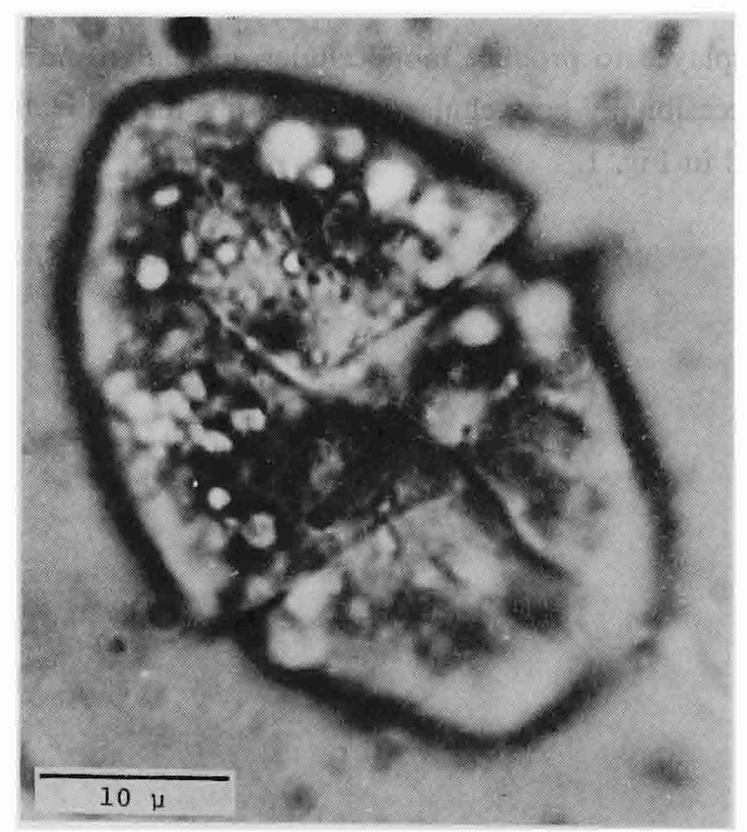

Fig. 2. Girdle and sulcus on ventral part of the cell of this species. The girdle displacement is estimated to be $\mathbf{0 . 2 3}$.

The girdle displacement amounted to 0.23 which is clearly larger than the upper limit 0.20 of the genus Gymnodinium and belongs to that of the genus Gyrodinium.

The sulcus extends into the epitheca just as Gyrodinium and is not limited within the hypotheca as Glenodinium.

This species has four nuclei in the tetracellular catena as shown in Fig. 1., and two nuclei in the dicellular catena. Therefore, it is clear that this species has not such cell structure as a syncytium. The tetracellular catena of Polykrikos has two nuclei by conjoining each two cells and by loosing a partition wall. Since this dinoflagellate does not form 
the syncytium structure, it is obvious that this species does not belong to the genus Polykrikos in accordance with the DAvis's classification ${ }^{6)}$.

GREUET $^{7)}$ reported that Polykrikos schwartzi BüTSCHLI has nematocysts, and LECAL ${ }^{8)}$ described that Polykrikos grassei, new species, has both nematocysts and trichocysts. However, the feature of Polykrikos is to have nematocysts and this was adopted as a criterion of the classification ${ }^{6)}$.

GREUET $^{9)}$ also indicated that the various types of nematocysts observed on Nematodinium have such transverse sections as concentric circles, whereas those of trichocysts possess a square or a rectangle in a circle. From these features, it was easy to distinguish trichocysts from nematocysts. Thus we checked whether this species has nematocysts or not and made clear the facts that this dinoflagellate has not any nematocyst but very many trichocysts in the cell as shown in Fig. 3.
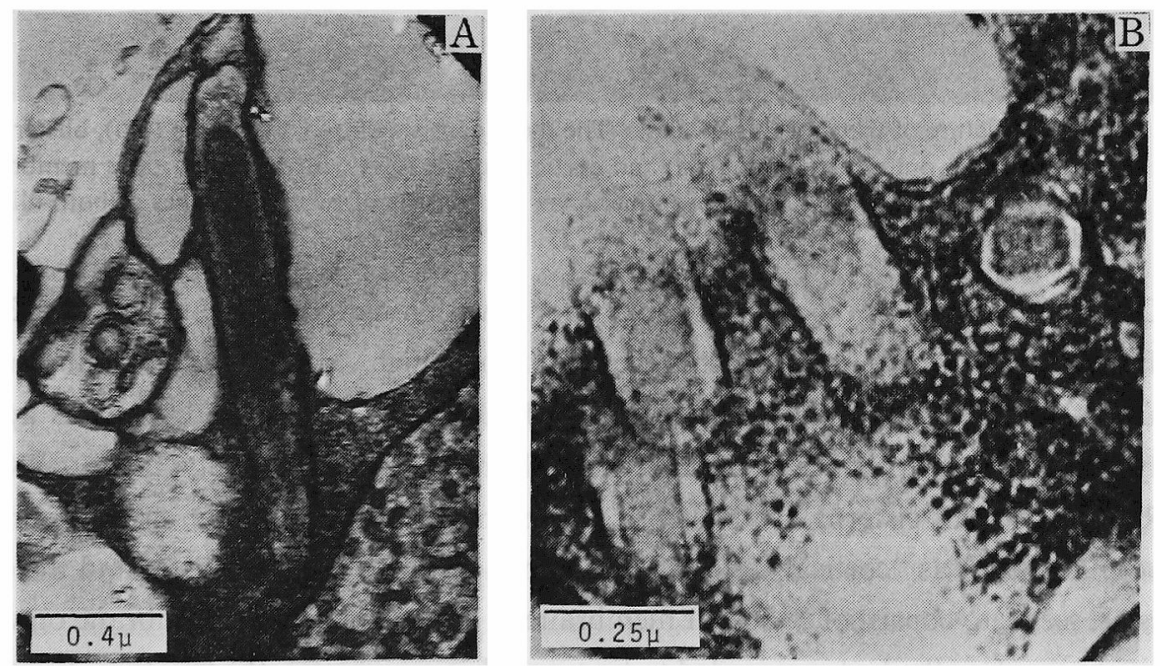

Fig. 3. Trichocysts in the cell of this species.
A: A longitudinal section of an undischarged trichocyst. The neck of the trichocyst contains a filament twisted intricately.
B: Transverse and oblique sections of the trichocysts.

From this observation, it is again obvious that this organism does not belong to the genus Polykrikos.

Previously, TANitsu and UCHIDA $^{10\rangle}$ described that the individual cell of Polykrikos consisting of two to sixteen cells could be Gymnodinium, but it is questionable to call them as Gymnodinium because of no nematocysts in the cells of Gymnodinium according to the criterion of the DAvis's classification.

DODGE and CRAWFORD ${ }^{11)}$ indicated the fine structure of the theca sections concerning the representative species of dinoflagellates. The fine structure of the theca section of this species is shown in Fig. 4. as an electron micrograph with magnification of $14.6 \times 10^{4}$. 


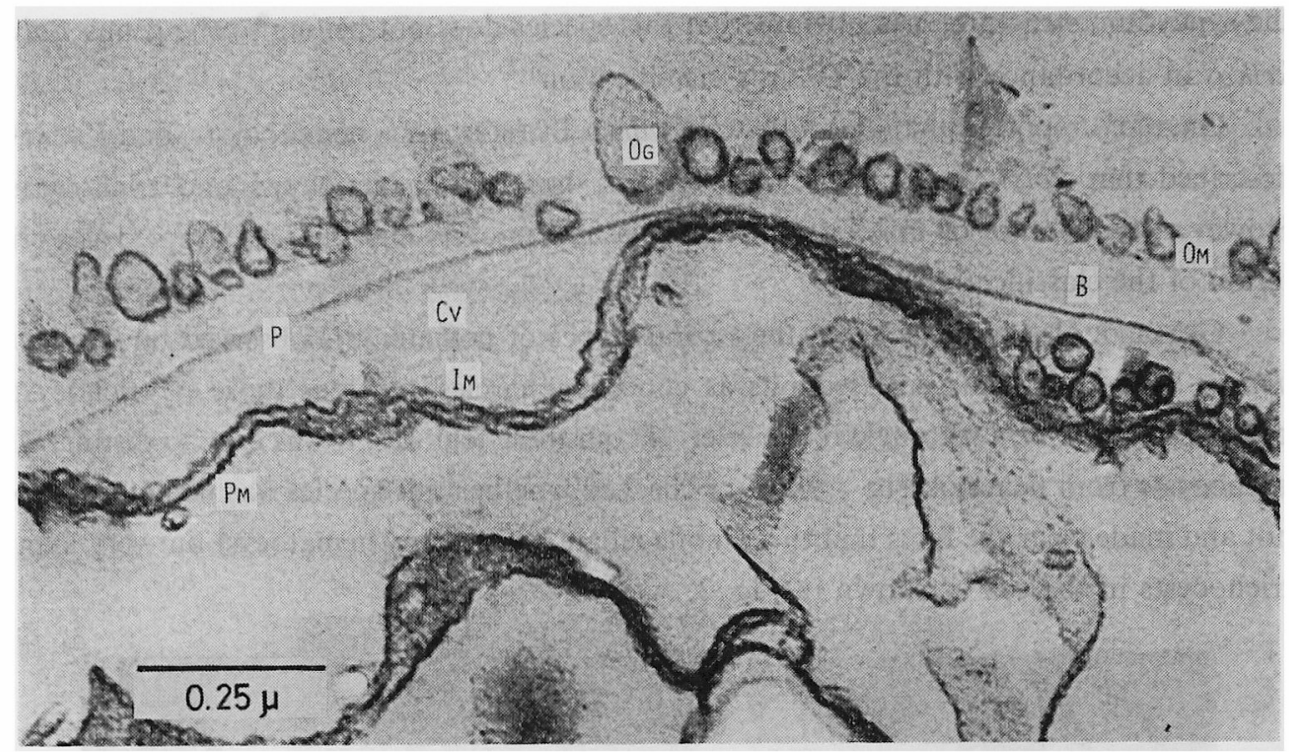

Fig. 4. Fine structure of theca of this species. The theca consists of ovoid granules (OG), blister (B) with very thin outer membrane (OM) and cortical vesicle $(\mathrm{Cv})$ with very thin inner membrane (IM). Plate or plate like amorphous inner layer (P) consists of two membranes of both blister and cortical vesicle.

On the uppermost of the theca, ovoid granules with longitudinal diameters 17-93 $\mathrm{m} \mu$, and the average $54 \mathrm{~m} \mu$, cover a very thin membrane on which vacant parts devoiding granules can be seen at random with spaces of $200-1,100 \mathrm{~m} \mu$. These ovoid granules appear merely to attach to the surface of the cisterna with the thickness probably $3.5 \mathrm{~m} \mu$. KUBAI and RIS ${ }^{12)}$ called this cisterna as "blister". Beneath this blister, another cisterna spreads. MignOT $^{13)}$ called it as "cortical vesicle". The boundary between the blister and the cortical vesicle seems to consist of two layer membranes. If the uppermost membrane on which the ovoid granules attached is regarded to be a unit thin membrane, the two layer boundary membrane must consist of two membranes of the blister and cortical vesicle. When the cell destruction of this dinoflagellate occured owing to variations of osmotic pressure, this organism did not leave the cell wall. Therefore, the membranes of the blister and the cortical vesicle could not have the reticular cell walls of mucopeptides as suggested by ROGERS $^{14)}$. DODGE ${ }^{15)}$ called these membranes as "plate", and KUBAI and Ris ${ }^{12)}$ used "plate like amorphous inner layer" for it. What Dodge called the plates vary in the shape and thickness from several $\mathrm{m} \mu$ to $2,700 \mathrm{~m} \mu$ depending on the species of dinoflagellates. However, the plate like membrane as seen in Gyrodinium cohnii is very thin, about $10 \mathrm{~m} \mu$ in thickness ${ }^{12}$. The dinoflagellate under the present study has the thickness of the plate to be only $7 \mathrm{~m} \mu$. In Fig. 4, a typical cell membrane consisting of protein, lipid core and protein can be seen beneath the cortical vesicle.

If this dinoflagellate is cultured in the mixture of natural sea water and $\mathrm{ASP}_{2} \mathrm{NTA}$ arti- 

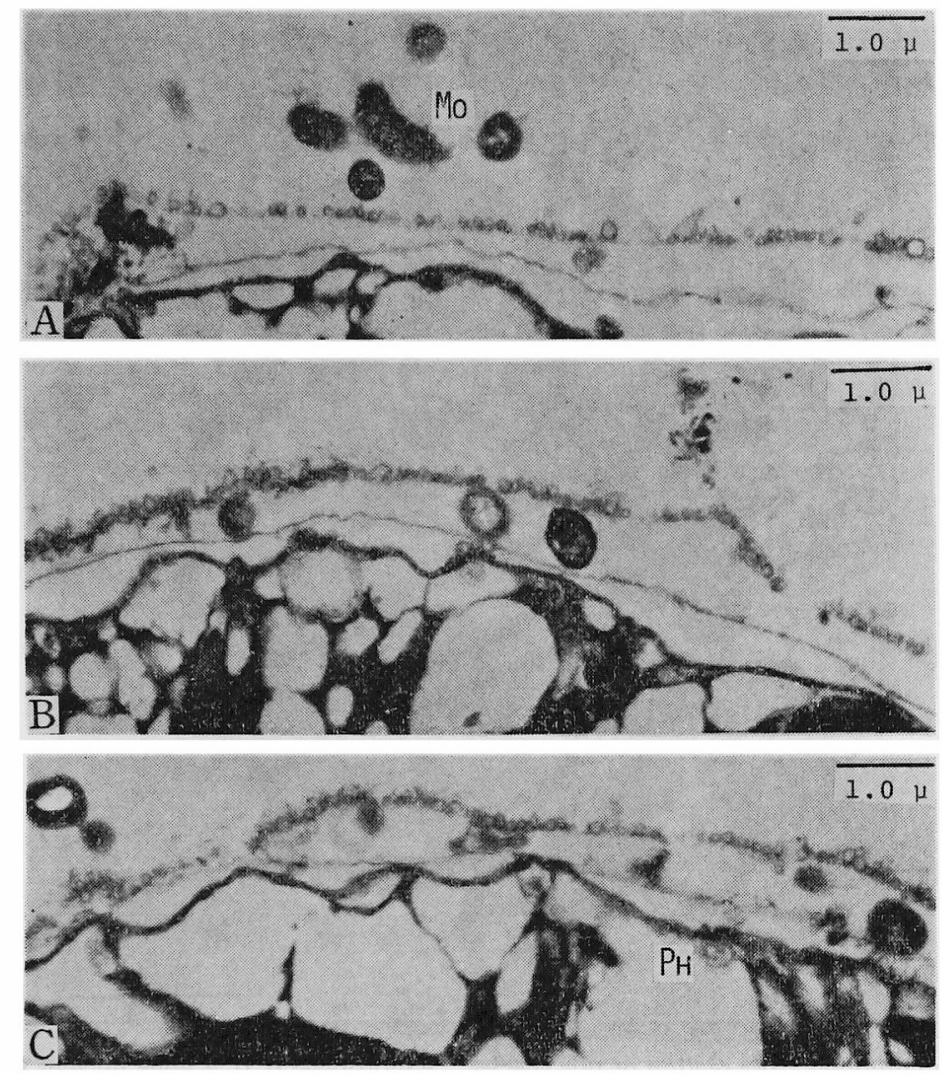

Fig. 5. Holozoic nutrition of this species. A: Microorganisms (MO) in external medium. B: Microorganisms in blister. C: A microorganism in phagocyte (PH).

ficial sea water, such microorganisms as bacteria, autospores and so on are incorporated into the blister and transferred to the cortical vesicle, then swallowed into the phagocytes as indicated in Fig. 5. While such holozoic nutrition is displayed, this species can do photosynthesis by aid of chloroplasts in the cell as shown in Fig. 6.

From these situations, it became clear that the nutrition of this dinoflagellate depends on both photosynthesis and incorporation of organic particles from the external medium, whereas the nutrition of Polykrikos schwartzi BüTSCHLI was shown to be holozoic ${ }^{7}$.

If the fine structure of the theca section of this species is compared with those of the representative dinoflagellates demonstrated by DODGE and CRAWFORD ${ }^{11)}$, it seems to be most close to that of a certain Gymnodinium except the uppermost granules as seen in Fig. 7.

However, it was clear that these representative Gymnodinium are devoid of the blister, and this species in the present study possesses the blister between the cortical vesicle and the granular surface. Therefore, this dinoflagellate differs from any dinoflagellates illustrated by them. 


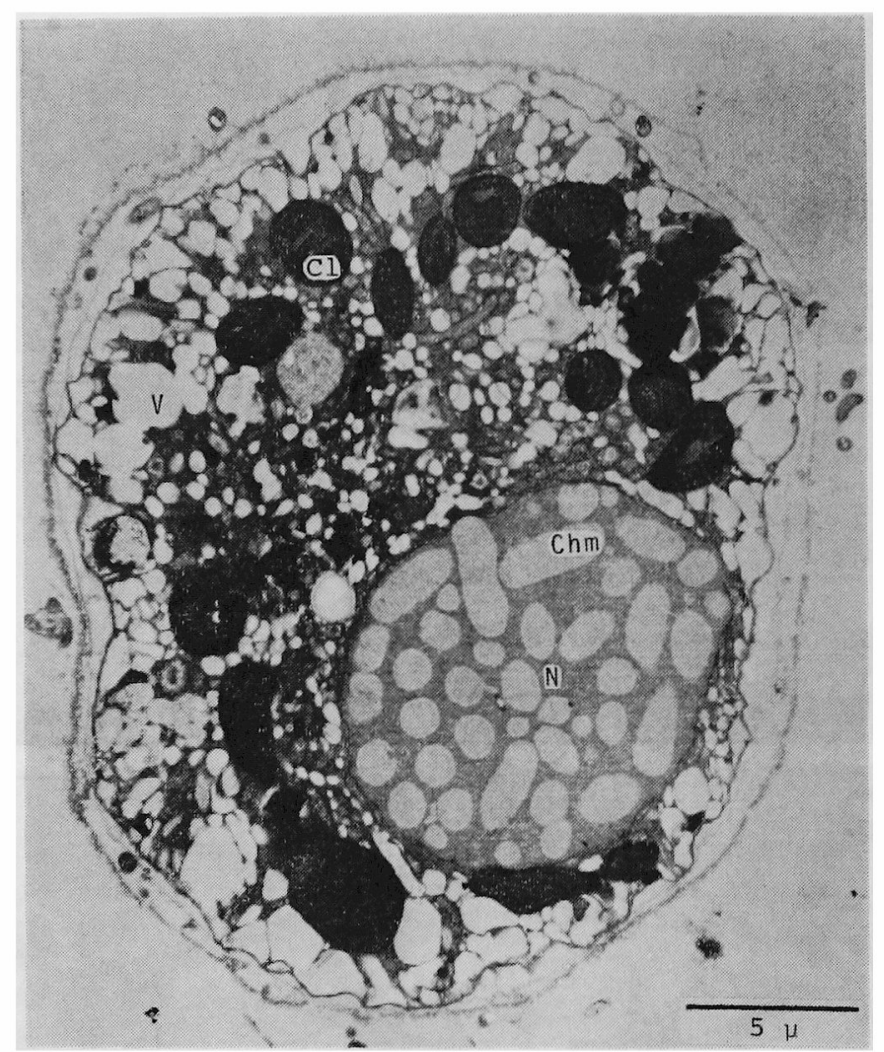

Fig. 6. A longitudinal cross section of this species. Chloroplast $(\mathrm{Cl})$, a huge nucleus $(\mathrm{N})$, in which many distinct chromosomes (Chm) exist, and vacuoles (V) are seen in this cell.

MIGNOT $^{13)}$ showed the ultrastructure of the theca section of Gymnodinium neglectum and those of several species of Gymnodinium which have, in common, the cortical vesicles beneath the blister in their thecae and described that these are capable of classifying dinoflagellates.

From these viewpoints, the theca structure of this species was compared with those of other species paying attention to the cortical vesicle, and it was found that Gymnodinium fuscum which also has the surface granules and actually possesses the cortical vesicle beneath the blister. This structure was similar to that of this species under studying but somewhat differed in the shape of the surface granules: Gymnodinium fuscum has peanuts like granules against the ovoid granules of this species. The thecae of Gymnodinium sp. indicated by SCHNEPF and DEICHGRÄBER ${ }^{18)}$ and Gymnodinium neglectum shown by MIGNOT $^{13)}$ differed from this species because of the defect of the surface granules.

As mentioned above, it is obvious that this species is close to the species of Gymnodinium, but it is ambiguous to conclude that this species belongs to the genus Gymnodinium, because Gyrodinium cohnii indicated by KUBAI and RIS ${ }^{12)}$ also has the blister and the cortical 
vesicle in its theca. The ultrastructure of the theca cross section of this species may allow this species to belong to the genus Gymnodinium, but the girdle displacement which is clearly beyond the upper limit of the genus Gymnodinium denys it and tells us that this species belongs to the genus Gyrodinium.

However, the electron micrographs of nuclei of such Gymnodinium as G. fuscum ${ }^{17)}$ and G. neglectum ${ }^{13)}$ indicated the obscure internal structure of the chromosomes. On the contrary, the chromosome of this species as shown in Fig. 8 is distinct and rather resembles
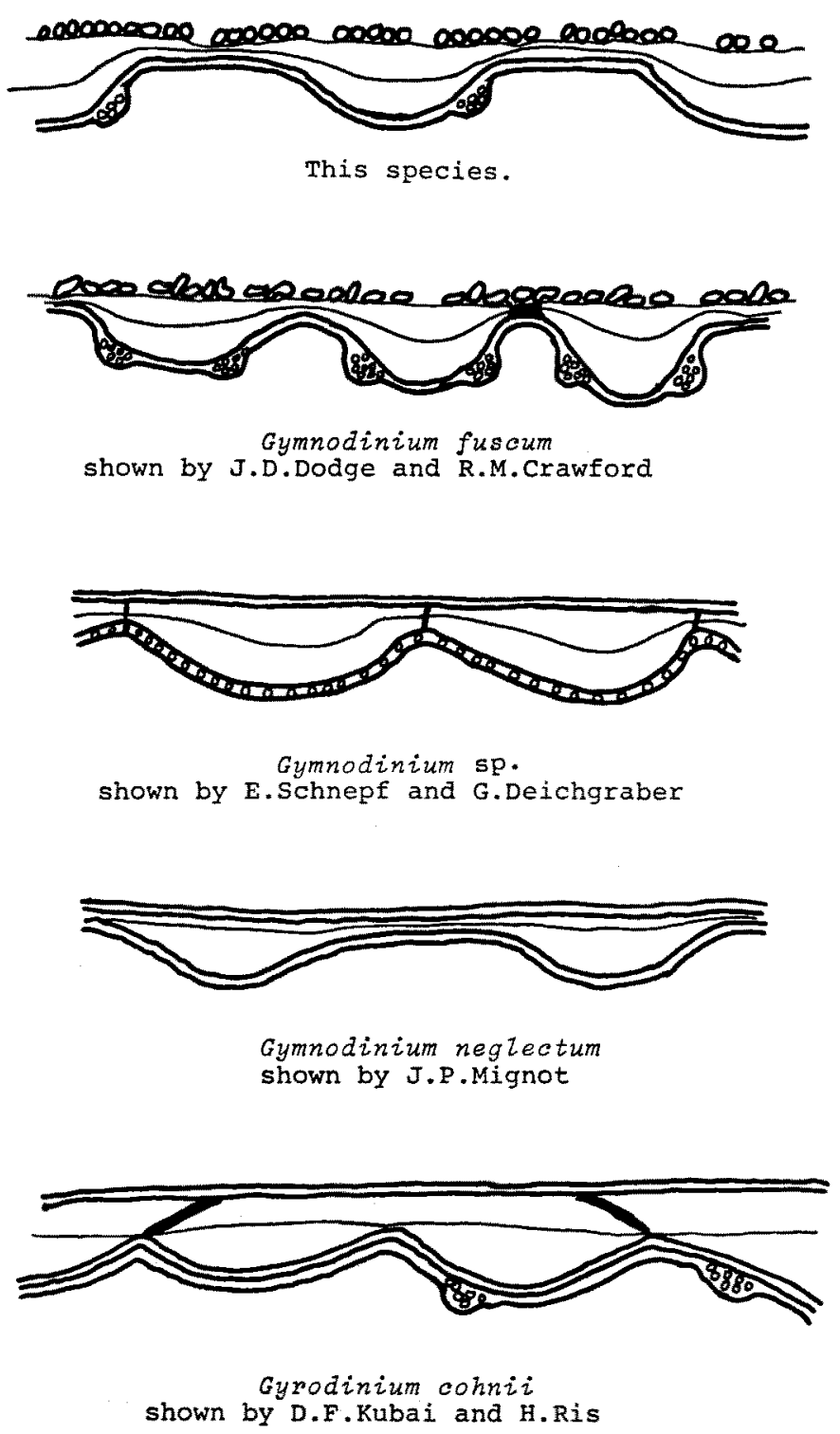

Fig. 7. Diagrams of various types of thecae observed in Gymnodinium and Gyrodinium spp. 


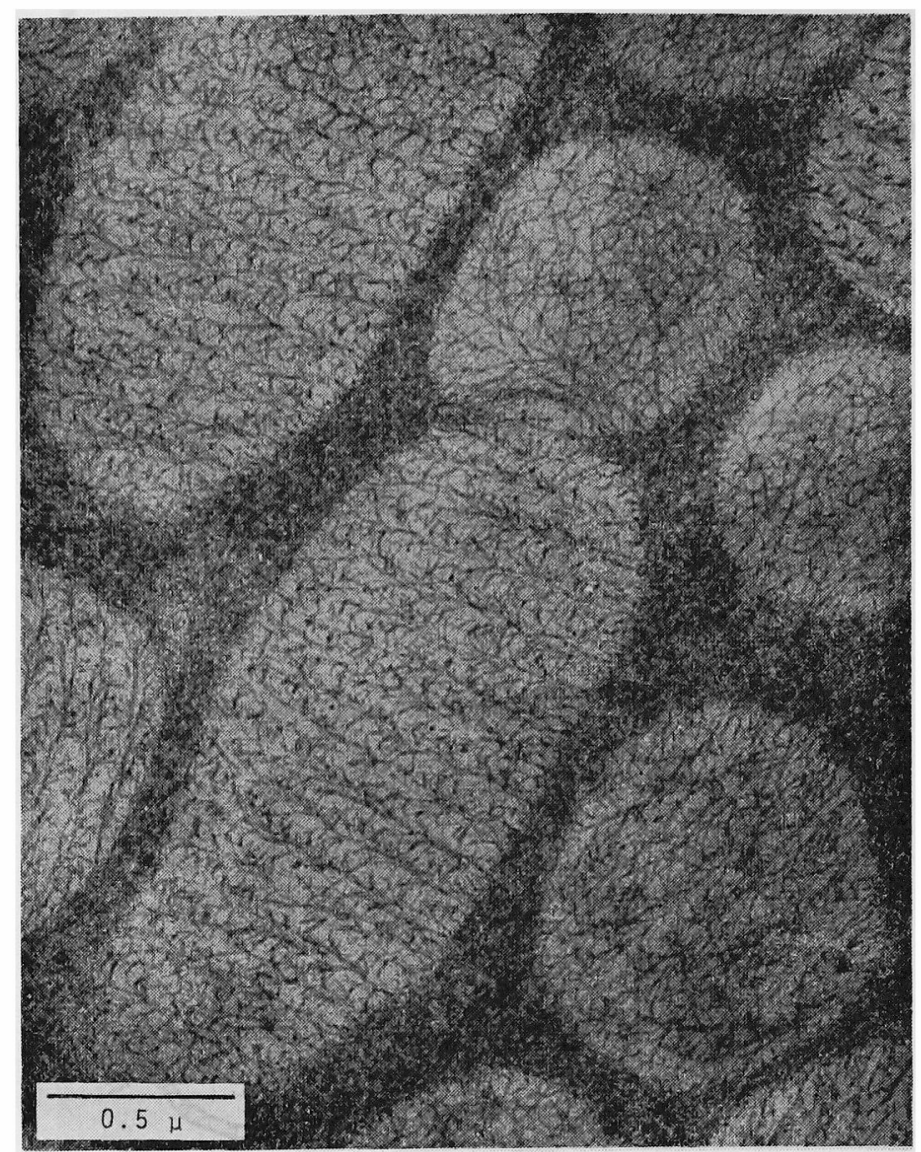

Fig. 8. Fine structure of chromosomes at the last interphase of this species.

those of Amphidinium ${ }^{18)}$, Peridinium ${ }^{19)}$ and Prorocentrum ${ }^{20)}$. When the chromosomes of this species were compared with those of G. fuscum, G. neglectum and Gyrodinium cohnii ${ }^{12)}$, there was found outstanding difference from them. Recently we were able to know the fine structure of Gymnodinium nelsoni ${ }^{21)}$ and the resemblance of the chromosomes between G. nelsoni and this species.

With these reasons, it also seems very difficult to classify this species with the appearance of the chromosomal sections.

As will be mentioned in the series of this paper, the length of the chromosomes of this species are exeremely long, about $18 \mu$ in the average at the early interphase and differ remarkably from those of Gymnodinium which length are about $7 \mu$ or so. By DodGE ${ }^{22)}$, it was described that the longest chromosome which had ever been observed on dinoflagellates was $15 \mu$ of Prorocentrum micans. With Gyrodinium fissum, it was also suggested that the chromosomes could be very long, although there was devoid of actual measuring ${ }^{22}$. It was reported that Gyrodinium cohnii has special plastids in the cell ${ }^{12)}$. This species 


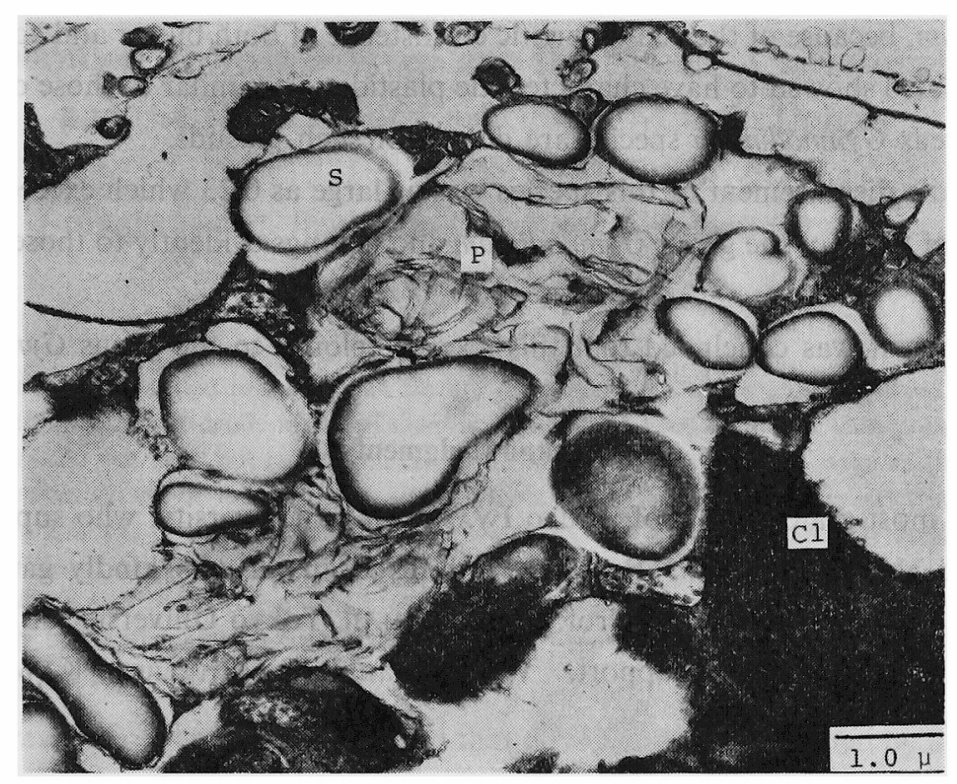

Fig. 9. Fine structure of plastids of this species, the feature of which is very similar to that of Gyrodinium cohnii. P: plastid, S: Starch granules and $\mathrm{Cl}$ : Chloroplast.

also has very similar plastids as seen in Fig. 9, but plastids are not found in the cells of the Gymnodinium $^{17)}$.

From these feature of the girdle displacement, the average length of chromosomes and the characteristic plastids this species is concluded to belong to the genus Gyrodinium but not the genus Gymnodinium.

This species is a marine catenate dinoflagellate. Gonyaulax ${ }^{23)}$, Polykrikos ${ }^{8)}, \mathrm{Co}-$ chlodinium $^{24)}$, Ceratium ${ }^{25)}$ and Gymnodinium ${ }^{26)}$ are well known species as catenate dinoflagellate, but we were not able to find out any report that Gyrodinium species can form the catenate cellular forms. This also suggests that this species may be a new species of the Gyrodinium.

\section{Conclusion}

A certain marine catenate dinoflagellate having been applied tentatively by present authors for testing carcinogens has been regarded to be Polykrikos schwartzi BüTsCHLI. However, there were found various features differing from those of Polykrikos schwartzi BüTSCHLI. The cells of this species revealed not to have the syncytium structure and any nematocyst, but numerous trichocysts in combination with both chloroplasts and phagocytes which proved this species to depend on the mixed nutrition. With these features, it was denied that this dinoflagellate belongs to the genus Polykrikos.

The fine structure of the theca suggested this species to belong to either Gymnodinium 
or Gyrodinium, because of the characteristic coexistence of both blister and cortical vesicle. This species also showed to have characteristic plastids very similar to those of Gyrodinium cohnii, whereas Gymnodinium species are devoid of such plastids.

The girdle displacement of this species was as large as 0.23 which exceeds clearly the upper limit of those of the genus Gymnodinium and belongs evidently to those of the genus Gyrodinium.

Therefore, it was concluded that this species belongs to the genus Gyrodinium.

\section{Acknowledgment}

We are most grateful to Prof. Hideo IWASAKI, Mie University, who supplied us with cultures and also to Prof. F. J. R. TAYLOR, UBC, Canada who kindly gave us helpful suggestions. We are indebted to Prof. Isamu YAMAJI, Tokyo University of Fisheries and Dr. Saburo Toriumi for their support. We are thankful to Mr. Yasuo KAWASAKI for his earnest help.

\section{References}

1) L. Provasoli, J. J. A. Mclaughlin and M. R. Droop: Arch. Mikrobiol., 25, $392-428$ (1957).

2) S. Ishio, T. YaNo and H. Nakagawa: in "Advances on Water Pollution Reserach", Pergamon Press, London, New York, 1971, pp. III-18/1-8.

3) R. G. ZingmaRk: Amer. J. Bot., 57, 586-592 (1970).

4) H. IWASAKI: This Bull, 37, 606-609 (1971).

5) H. Kushida: in "Ultrathin sectioning", Bunkodo, Tokyo, 1971, pp. 202.

6) C. C. Davis: in "The Marine and Freshwater Plankton", Michigan State Univ. Press, 1955, pp. 175181.

7) C. Greuet: C. R. Acad. Sci. Paris, 275, 1239-1242 (1972).

8) J. LeCal: Bull. Soc. Hist. Nat. Toulouse, 108, 302-324 (1972).

9) C. Greuet: Protistologica, 7, 345-355 (1971).

10) N.TANitsu and H. UCHIDA: in "Taxonomical Table of Zoology", Maruzen, Tokyo, 1952, pp. 9-12.

11) J. D. Dodge and R. M. Crawford: Bot J. Linn. Soc., 63, 53-67 (1970).

12) D. F. Kubai and H. Ris: J. Cell Biol., 40, 508-528 (1969).

13) J. P. Mignot: Protistologica, 6, 267-281 (1970).

14) H. J. Rogers: The Biosynthesis of Structure, 15th Symp. Soc., Gen. Microbiol., 186-219 (1965).

15) J. D. Dodge: in "The Fine Structure of Algal Cells", Academic Press, New York, 1973, pp. 27.

16) E. Schnepf and G. Deichgräber: Protoplasma, 74, 411-425 (1972).

17) J. D. Dodge and R. M. Crawford: New Phytol., 68, 613-618 (1969).

18) K. G. Grell and K. E. Wohlfarth-BottermanN: Zeitschrift für Zellforschung, 47, 7-17 (1957).

19) G. Messer and Y. Ben-Shaul: J. Protozool., 16, 272-280 (1969).

20) J. D. DodGe and B. T. BibBY: Bot. J. Linn. Soc., 67, 175-187 (1973).

21) L. R. Mendiola, C. A. Price and R. R. L. Guiliade: Science, 153, 1661-1663 (1966).

22) J. D. Dodge: in "The Chromosomes of the Algae" (M. B. E. Godward, ed.), Arnold, London, 1966, pp. 96-115.

23) R. N. Tomas: J. Protozool., 21, 316-321 (1974).

24) Estela de Sousa E Silva: ibid., 14, 745-754 (1967).

25) R. WetherbeE: J. Ultra. Res., 50, 58-64 (1965).

26) I. Yamaj: in "Illustrations of the Marine Plankton of Japan", Hoikusha Publishing Co., LTD, Tokyo, 1966, pp. 75.

27) H. J. Evans and D. Scort: Proc. Roy. Soc., B. 173, 491-512 (1969). 